\title{
A short argument for truthmaker maximalism
}

\section{Maximalism}

Each truth has a truthmaker: an entity in virtue of whose existence that truth is true. So say truthmaker maximalists. Arguments for maximalism are hard to find, whereas those against are legion. Most accept that maximalism comes at a significant cost, which many judge to be too high. The scales would seem to be balanced against maximalism. Yet, as I show here, maximalism can be derived from an acceptable premise which many will pre-theoretically accept. I'll argue for the premise $(\mathbb{2} 2)$, give the argument for maximalism $\left(\mathbb{S}_{3}\right)$ and consider two objections $(\mathbb{4})$.

\section{The Premise}

The argument's crucial premise is:

(P) For each truth $A$, a truthmaker for $A$ is logically possible.

The sense of logical possibility in question is intended to be weak: ideal conceivability, conceptual coherence, or logical consistency, rather than 'substantial' metaphysical possibility. On the intended sense, logically possible situations are consistent and closed under logical consequence, and they respect two truthmaking principles:

(F) If $A$ has a truthmaker, then $A$ is true;

(D) If $A \wedge B$ has a truthmaker, then so do $A$ and $B$.

Other than these very minimal constraints, we can let the notion of logical possibility be as unconstrained as we like. Throughout, I'll use 'possible' in this weak sense.

(Note that $(\mathrm{P})$ is not the (stronger) assumption that maximalism is logically possible. That requires a situation containing a truthmaker for each truth of that situation. By contrast, $(\mathrm{P})$ requires only that, for each truth, a possible situation contains a truthmaker for it. Those situations need not be compossible, as far as (P) is concerned.)

I will offer an argument that $(\mathrm{P})$ is plausible, in two steps. The first contends that at least some maximalist-friendly ontology is possible (in the weak sense (P) requires). The second step then offers an inductive case for $(\mathrm{P})$. The first step is the 
easy one. There are a plethora of maximalist approaches available, all drawing on different ontology, and the argument needs only that at least one of them is consistent. Naysayers have a hard time here: to claim a viewpoint is logically inconsistent, you'll need a proof. And what's more, you'll need one for each maximalist theory.

Arguments against maximalism rarely attempt to demonstrate inconsistency. Perhaps truthmakers for 'negative' truths are ruled out by some metaphysical principle (Molnar 2000, 84). Perhaps true negative existentials are 'true for lack of false-makers' (Lewis I992, 216). Perhaps truthmaking does not require entities as truthmakers (Melia 2005; Schnieder 2006). Perhaps truthmaker theory as a whole 'lacks a proper motivation' (Liggins 2008, I92), so that 'we have no reason to believe the principle' (Williamson I999, 253). Even if true, none of this shows that maximalist-friendly ontology is inconsistent. An entity may be logically possible even if it conflicts with a metaphysical principle, even if it is theoretically unnecessary, and even if all arguments for it are poorly motivated.

Consider, for example, the debate over truthmakers for 'negative' truths, such as that there is no penguin in my bath. Candidates, including totality facts (Armstrong I997; 2004), negative facts (Russell I985) and absences (Kukso 2006; Martin 1996), are typically rejected on specifically metaphysical, not logical, grounds. Mumford (2007) offers an argument that these 'negative' entities are incoherent, because they would both exist and not exist. But that's a straw man: the claim is that the absence of a unicorn exists, whereas the unicorn doesn't. Such entities may be unpalatable (especially for those who detest necessary connections and exclusions), but they are surely logically consistent.

Even if all these 'negative' entities fail the test, there are other maximalist approaches. Lewis and Rosen (2003) rely on possibilia and tricks with counterpart relations. I doubt mere possibilia exist, but Lewis's pluriverse is surely consistent. Cameron (2008) relies only on the actual world being its only counterpart. I doubt it is, but the theory is surely consistent. Schaffer (2OIO) relies only on reality, considered as a whole. Unlike him, I doubt its parts depend on the whole. But that is a metaphysical disagreement: his view is surely consistent.

Williamson (I999) argues that maximalism (of any kind) is inconsistent with the Converse Barcan Formula (CBF, $\square \forall x A \rightarrow \forall x \square A$ ). For if a truthmaker for $A$ exists, by $(\mathrm{CBF})$ it exists in all accessible worlds and so $A$ is true in all worlds. So if all truths have a truthmaker, all truths are necessary, which is absurd. Everyone should be worried by this line of reasoning. CBF implies that, at each accessible world, something is identical to me. Yet surely I could have failed to exist. So either CBF is false, or else there is some other, non-logical sense in which I could have failed to exist: perhaps I could have been a non-concrete entity (Williamson 2002). But in that case, we can allow truthmaking states of affairs to exist without obtaining. Either way, there is no argument against the possibility of maximalism here. 
The mere possibility of maximalist-friendly entities doesn't yet secure $(\mathrm{P})$ in full generality. But consider some representative truths: Obama is male; wombats are marsupials; $1+1=2$; there is no greatest prime number, scarlet things are red. (Now add many more of your own.) For each, it's logically possible that a truthmaker for it exists. The examples cover specific and general, concrete and abstract, contingent and necessary, analytic and synthetic cases. (Logical and analytic cases are not special in this regard: whatever makes it true that Obama is male thereby makes true both 'either Obama is or isn't male' and the analytic 'either Obama is male or he isn't a bachelor'.) So we have a good inductive base for claims about truth. Reasoning inductively, we defeasibly infer the general claim, (P). That gives us warrant - not a proof, but reason nonetheless - to accept (P). $(\mathrm{P})$ is (defeasibly) justified. I'll consider whether this warrant survives objections to $(\mathrm{P})$ in $\mathbb{} 4$.

\section{The Argument}

Suppose for reductio that some $A$ is true but lacks a truthmaker. By $(\mathrm{P})$, it is logically possible for that conjunction to have a truthmaker. That supposed possibility is a situation in which there is a truthmaker for: $A$ and $A$ has no truthmaker. Then both conjuncts are true and so $A$ has no truthmaker in that situation. But since both conjuncts have a truthmaker in the situation, $A$ has one: contradiction. By reductio, every truth has a truthmaker.

The reasoning is formally sound. Let us abbreviate 'there exists a truthmaker for $A$ ' by 'Tм $A$ ' and 'it is logically possible that $A$ ' by ' $\diamond A$ '. The additional premises are that 'TM' is factive and distributes over conjunction:

(F) $\operatorname{TM} A \rightarrow A$

(D) $\operatorname{TM}(A \wedge B) \rightarrow \mathrm{TM} A \wedge \mathrm{TM} B$

and that whatever is provably false is provably impossible:

$$
\text { (N) } \frac{\vdash \neg A}{\vdash \neg \diamond A}
$$

(This is none other than the usual necessitation rule in disguise.) Then we may reason as follows:
I. $\quad \operatorname{TM}(A \wedge \neg \mathrm{TM} A)$
assumption
2. $\mathrm{TM} A \wedge \mathrm{TM} \neg \mathrm{TM} A$
I, (D)
3. $\mathrm{TM} A \wedge \neg \mathrm{TM} A$
2, (F)
4. $\neg \mathrm{TM}(A \wedge \neg \mathrm{TM} A)$
I, 3 , reductio
5. $\neg \diamond \mathrm{TM}(A \wedge \neg \mathrm{TM} A)$
$4,(\mathrm{~N})$
6. $(A \wedge \neg \mathrm{TM} A) \rightarrow \diamond \mathrm{TM}(A \wedge \neg \mathrm{TM} A)$
7. $\neg(A \wedge \neg \mathrm{TM} A)$
(P)
8. $A \rightarrow \mathrm{TM} A$
5,6, modus tollens
7 , logic 
We first prove that $\mathrm{TM}(A \wedge \neg \mathrm{TM} A)$ is inconsistent $(\mathrm{I}-3)$ and hence impossible (5). $(\mathrm{P})$ then allows us to infer $\neg(A \wedge \neg \mathrm{TM} A)(7)$ and hence maximalism, (8). So (P) entails maximalism.

The reasoning is familiar from the Church-Fitch 'paradox' of knowability (Church 2009; Salerno 2009), which is no genuine paradox, merely a surprising piece of reasoning. That same, I say, applies here.

\section{Objections}

Having seen the argument, perhaps you're now minded to reject (P). As I noted in $\$ 2$, your best bet is to deny the induction step to $(\mathrm{P})$, on the grounds that the base isn't sufficiently broad. If our examples include truthmaking-talk, then we'll find a false instance: $A \wedge \neg \mathrm{TM} A$. This move is dialectically ineffective, however, for it assumes the falsity of maximalism in taking $A \wedge \neg \mathrm{TM} A$ as an example truth. Whether there is such a truthmakerless truth $A$ is precisely what is in question. An effective counterexample to $(\mathrm{P})$ requires an uncontested truth, for which there is no logically possible truthmaker. But such truths, I suggest, are hard to come by.

Perhaps the argument proves too much. It can be run for any concept satisfying (F) and (D), and so we appear to be able to deduce the existence of all manner of unappealing omniscient beings, evil demons and the like, merely from assuming the logical consistency of the notion. We're in bad company. Let's grant that (e.g.) omniscient beings are indeed possible. The analogue of $(\mathrm{P})$ doesn't follow, however. It requires that, for any $A$, it is possible for an omniscient being (or demon or whatever) to exist and know that $A$. Counterexamples are easily found: 'there are no minds', 'there are no beliefs', 'nothing but a spacetime point exists'. To find the corresponding version of $(\mathrm{P})$ plausible, one would have to posit a very close conceptual link from truth to knowledge: perhaps that knowledge constitutes truth. That doesn't seem plausible and so there's no bad company objection here. (And if it is, the company isn't so bad.)

Acknowledgements: Thanks to David Ingram, Jonathan Tallant, two referees and an editor for helpful suggestions.

\section{References}

Armstrong, D. I997. A World of States of Affairs. Cambridge: Cambridge University Press.

Armstrong, D. 2004. Truth and Truthmakers. Cambridge: Cambridge University Press. Cameron, R. 2008. How to be a truthmaker maximalist. Nous 42: 4IO-2I.

Church, A. 2009. Referee reports on Fitch's 'A Definition of Value'. In New Essays on the Knowability Paradox, ed. J. Salerno, I3-20. Oxford: Oxford University Press.

Kukso, B. 2006. The reality of absences. Australasian Journal of Philosophy 84: 21-37. 
Lewis, D. I992. Critical notice of D.M. Armstrong's A Combinatorial Theory of Possibility. Australasian Journal of Philosophy 70: 2 I I-24.

Lewis, D. and Rosen, G. 2003. Postscript to 'things qua truthmakers': negative existentials. In Real Metaphysics, ed. H. Lillehammer and G. Rodriguez-Pereyra, 39-42. London: Routledge.

Liggins, D. 2008. Truthmakers and the groundedness of truth. Proceedings of the Aristotelian Society I08: I77-96.

Martin, C. I996. How it is: entities, absences and voids. Australasian Journal of Philosophy 74: 57-65.

Melia, J. 2005. Truthmaking without truthmakers. In Truthmakers: the Contemporary Debate, ed. H. Beebee and J. Dodd, 67-84. Oxford: Oxford University Press.

Molnar, G. 2000. Truthmakers for negative truths. Australasian Journal of Philosophy 78: 72-86.

Mumford, S. 2007. Negative truth and falsehood. Proceedings of the Aristotelian Society I07: 45-7I.

Russell, B. I985. The philosophy of logical atomism. In The Philosophy of Logical Atomism, ed. D. Pears, 35-I 55. La Salle: Open Court.

Salerno, J. 2009. Introduction. In New Essays on the Knowability Paradox, ed. J. Salerno, I-IO. Oxford: Oxford University Press.

Schaffer, J. 20I0. The least discerning and most promiscuous truthmaker. The Philosophical Quarterly 60: 307-24.

Schnieder, B. 2006. Truth-making without truth-makers. Synthese I 52: 2 I-46.

Williamson, T. I999. Truthmakers and the converse barcan formula. Dialectica 53: 25370.

Williamson, T. 2002. Necessary existents. In Logic, Thought and Language, ed. A. O'Hear, 233-5 I. Cambridge: Cambridge University Press. 